Artvin Çoruh Üniversitesi

Orman Fakültesi Dergisi

ISSN:2146-1880, e-ISSN: 2146-698X

Yıl: 2021, Cilt: 22, Sayı:1, Sayfa: 26-41

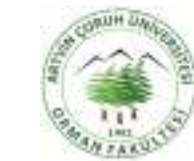

ofd.artvin.edu.tr
Artvin Coruh University

Journal of Forestry Faculty

ISSN:2146-1880, e-ISSN: 2146-698X

Year: 2021, Vol: 22, Issue:1, Pages: 26-41

\title{
(c) (1) \\ Mor Çiçekli Ormangülünün (Rhododendron ponticum L.) günümüz ve gelecekteki iklim koşullarına göre yayılış alanlarının modellenmesi
}

\section{Modeling of the distribution of Purple-flowered Rhododendron (Rhododendron ponticum L.) under the current and future climate conditions}

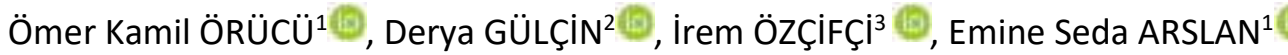 \\ ${ }^{1}$ Süleyman Demirel Üniversitesi, Mimarlık Fakültesi, Peyzaj Mimarlığı Bölümü, Isparta \\ ${ }^{2}$ Adnan Menderes Üniversitesi, Ziraat Fakültesi, Peyzaj Mimarlı̆ı̆ Bölümü, Aydın \\ ${ }^{3}$ Ankara Üniversitesi, Fen Bilimleri Enstitüsü, Peyzaj Mimarlığı Anabilim Dalı, Ankara
}

\section{Eser Bilgisi / Article Info}

Araştırma makalesi / Research article

DOI: 10.17474/artvinofd.834174

Sorumlu yazar / Corresponding author

Emine Seda ARSLAN

e-mail: sedaarslan@sdu.edu.tr

Geliş tarihi / Received

01.12 .2020

Düzeltme tarihi / Received in revised form

28.12.2020

Kabul Tarihi / Accepted

28.12.2020

Elektronik erişim / Online available

12.05.2021

Anahtar kelimeler:

Rhododendron ponticum $L$.

CNRM-1

Tür dağılım modeli

Değişim analizi

MaxEnt

\section{Keywords:}

Rhododendron ponticum $L$.

CNRM-1

Species distribution model

Change analysis

MaxEnt

\begin{abstract}
Özet
Bu çalışmanın amacı mor çiçekli orman gülü Rhodendron ponticum L. 'nin maximum entropi algoritması kullanılarak günümüz ve gelecek potansiyel yayılış alanlarının iklim senaryolarına göre modellenmesidir. İki aşamalı olarak yürütülen bu çalışmanın birinci aşamasında R. ponticum L.'nin çalışma alanı (Türkiye, Gürcistan ve Rusya sınırları) içerisindeki yayııışını temsil eden örnek noktalara ait (presence data) veriler ve biyoklimatik değişkenler kullanılmıştır. Yüksek korelasyonu ve çoklu doğrusallığı önlemek amacıyla, Worldclim 2.1 versiyonu 2.5 dakika (yaklaşık $20 \mathrm{~km}^{2}$ ) konumsal çözünürlükteki 19 biyoklimatik değişken Pearson Korelasyon analizi yapılarak 8 değişkene indirgenmiştir. İkinci aşamada ise türün yayılış alanlarının iklim değişiminden nasıl etkileneceğini belirlemek için CMIP6 modellerinden olan CNRM-CM6-1 iklim değişikliği modeli kullanılmış, SSP2 4.5 ve SSP5 8.5 'e senaryolarına göre $2041-2060$ ve $2081-2100$ periyotlarına ait potansiyel yayılış alanı MaxEnt 3.4.1 programı kullanılarak modellenmiştir. Ayrıca, tür için tahmin edilen günümüz ve gelecekteki potansiyel yayılış alanları arasındaki alansal ve konumsal farklar, değişim analizi ile ortaya konulmuştur. Sonuçta, $R$. ponticum L.'nin potansiyel yayılış alanlarına göre üretilen bilginin teoriden pratiğe dönüşmesindeki temel faydalar sürdürülebilir peyzaj yönetimi kapsamında tartışılmıştır.
\end{abstract}

\begin{abstract}
This study aims to model the present and future potential distribution of Rhododendron ponticum L. species according to diverse climate scenarios using maximum entropy. Carried out in two stages, the present study utilized presence data representing natural distribution of R. ponticum L. species in Turkey, Georgia, and Russia. In the first stage, we determined variables of the climate models and focused on 19 bioclimatic variables (in 2.5 minute, or approximately $20 \mathrm{~km}^{2}$, spatial resolution in Wordclim version 2.1) obtained for presence data from sample points. In order to prevent from high correlation and multi-collinearity, bioclimatic variables were reduced to 8 variables by performing Pearson correlation analysis. In the second stage, CNRM-CM6-1 climate change model, which is one of the CMIP6 models, was used to determine how the distribution areas of the species will be affected by climate change. Within this scope, the potential distribution areas of the species under the SSP2 4.5 and SSP5 8.5 scenarios in the periods 2041-2060 and 2081-2100 were modelled by means of the MaxEnt 3.4.1 software. Furthermore, spatial differences between the present and future potential distribution of the species were assessed by change analysis. In conclusion, this study suggested using produced knowledge and transforming them from theory to practice for underpinning sustainable landscape management.
\end{abstract}

\section{GiRiş}

Yeryüzündeki habitatlar, yüzyıllar boyunca farklı iklim koşullarına maruz kalarak varlığını sürdürmüştür. Değişen iklim koşulları sonucunda meydana gelen döngüler, türlerin farklı enlemlerde hem karasal hem de deniz ekosistemlerindeki mekânsal yayılışlarında varyasyon yaratmıştır (Simi ve ark. 2017). Bu süreçte oluşan ekolojik ve biyocoğrafik tepkiler, karasal toplulukların defalarca kez yeniden organize olmasını gerektirmiş, buna bağlı olarak türlere ait coğrafi aralıkların hem konumu hem de genel uzantısındaki değişiklikler yerel ve bölgesel popülasyonda hızlı artış ve azalmalara neden olmuştur (Williams ve Jackson 2007, Dawson ve ark. 2011). Değişen iklim koşullarının genel sonuçlarından birisi, dünya genelinde bitki türlerinin coğrafi dağılımının önemli ölçüde değişmesidir (Scheper ve ark. 2013, Fortunel ve 
ark. 2014, Scheffers ve ark. 2016). Bu değişiklik büyük ölçüde, büyüme mevsimi boyunca artan sıcaklvvıklar ve azalan yağışlarla bağlantılıdır (IPCC 2014). iklim değişikliğinin türler üzerindeki etkisine atıf yapan birçok çalışma, küresel sıcaklık artışının etkilerini araştırmış, sonuç olarak türlerin kutuplara (daha yüksek enlem) ve daha yüksek rakıma göç edeceğini öne sürmüştür (Chen ve ark. 2011, Ehrlén ve Morris 2015, Fei ve ark. 2017, Dai ve ark. 2020).

Doğal peyzajların bir parçası olan orman alanlarındaki bitki türlerinin iklim değişikliğinin olumsuz etkilerine maruz kalması yalnızca ekosistemleri değil, aynı zamanda ekosistemlerin sağladığı hammadde temini (kereste, tıbbi bitki vb.), karbon depolama veya biyolojik çeşitliliğin korunması gibi ekosistem hizmetlerini de ilgilendirmektedir (Dawson ve ark. 2011, Bouchard ve ark. 2019). Güncel araştırmalar, değişen iklim koşulları nedeniyle oluşacak habitat kaybının önümüzdeki yıllarda küresel biyoçeşitliliği tehdit edeceğini öngörmektedir (Dyderski ve ark. 2018, Li ve ark. 2020). Bu nedenle, türlerin mevcut ve gelecekteki iklim koşullarına göre mekânsal dağılımının modellenmesi, biyoçeşitlilik üzerindeki tehditlerin azaltılmasına yönelik doğa koruma temelli stratejilerin belirlenmesi ve peyzaj yönetimi kapsamında türlerin sürdürülebilirliğinin sağlanması bakımından oldukça önemlidir (Oliver ve ark. 2016, Dimobe ve ark. 2020, Akyol ve ark. 2020).

Tür Dağılım Modelleri (TDM), belirli bir türün potansiyel dağılımını belirlemek için türlere ait var/yok verilerini çevresel değişkenlerle birleştirir (Austin 2007, Elith ve Leathwick 2009, Kramer-Schadt ve ark. 2013, Norberg ve ark. 2019). TDM arasında, maksimum entropi algoritması (MaxEnt), belirli çevresel koşullar altında tür dağııım entropisini maksimize ederek türlerin potansiyel dağııım olasılığını tahmin etmektedir (Phillips ve ark. 2006). Bu model, tahmin doğruluğu açısından diğer TDM'lerden daha iyi performans gösterir ve küçük örnek boyutu toleransına sahiptir (Hernandez ve ark. 2006, Merow ve ark. 2013). MaxEnt, bitki türlerinin korunması, nesli tükenmekte olan ve endemik türlerin yönetimi, istilacı türler gibi çeşitli bitki türlerinin mevcut koşullar altında tür dağılımlarını ve iklim değişikliği senaryolarını modellemek için yaygın olarak kullanılmıştır (Qin ve ark.
2017, Thapa ve ark. 2018, Romero ve ark. 2018, Ferrarini ve ark. 2019, Abdelaal ve ark. 2019, Rojas Briceño ve ark. 2020, Dagnino ve ark. 2020). MaxEnt modeline ve coğrafi bilgi sistemlerine dayalı olarak, türlerin potansiyel coğrafi dağılımları ve iklim değişikliği senaryolarına göre biyolojik çeşitliliğe yönelik potansiyel riskler tahmin edilebilir. Bu bağlamda, iklim değişikliğinin küresel biyoçeşitlilik üzerindeki olumsuz etkisini azaltmak için çevresel karar verme sürecinde güçlü stratejiler oluşturulabilir (Kim ve ark. 2020, Zhao ve ark. 2020).

Hükümetlerarası İklim Değişikliği Paneli (IPCC), çok sayıda araştırmacının bir araya gelerek ve standart iklim senaryoları paketi içeren değerlendirme raporlarını düzenli olarak yayınladığı bir oluşumdur. Senaryolar, mevcut ve gelecekteki sera gazı emisyonları ve bunların iklim üzerindeki etkileri hakkında bilgi ve varsayımlara dayanmaktadır (IPCC 2014, Djalante 2019). Iklim bilimine odaklı eşleştirilmiş model karşılaştırma projeleri (CMIP) olarak koordine edilen modeller, daha yüksek çözünürlükte güncel verileri içerecek şekilde düzenli olarak güncellenmektedir. En son (beşinci) hazırlanan IPCC değerlendirme raporu (AR5) 2013'de yayınlanmıştır. AR5, dünya sıcaklık ortalamasının 2100 yılına kadar 0.3$4.5^{\circ} \mathrm{C}$ artacağını öngörmektedir (IPCC 2014). IPCC, üç özel rapordan oluşan altıncı rapor (AR6) üzerinde çalışmakta ve üretilecek sentez raporun 2022'de yayınlanması beklenmektedir.

Türlerin potansiyel dağılım alanları ve ekolojik koşulları içeren mekânsal bilgiler, tehdit altındaki habitatların korunmasına ve restorasyonuna yardımcı olarak türlerin sürdürülebilirliğine katkı sağlayabilir (Sarıkaya ve Örücü 2019, Örücü 2019, Arslan ve ark. 2020, Kaky ve ark. 2020). Bu çalışmanın amacı, Türkiye'de sınırlı yayılış gösteren ve peyzajda ekonomik, ekolojik, tıbbi, görsel özellikleri ile dikkat çeken türlerden birisi olan mor çiçekli ormangülünün mevcut ve gelecekteki potansiyel yayılış alanlarını küresel iklim değişikliği senaryoları kapsamında çalışma alanında modellemektir. Bu amaçla çalışma, aşağıdaki sorulara yanıt aramaktadır:

1) Mor çiçekli ormangülünün (R. ponticum L.) CNRMCM6-1 iklim değişikliği modeline göre günümüz ve gelecekteki potansiyel coğrafi yayılışı nasıldır? 
2) SSP2 4.5 and SSP5 8.5 iklim değişikliği senaryolarına göre, $R$. ponticum L.'nin günümüz ve gelecekteki dağıımının alansal ve konumsal uygunluğunda nasıl bir değişiklik olacaktır?

\section{MATERYAL VE YÖNTEM}

Mor çiçekli ormangülü olarak bilinen Rhododendron ponticum L. bu çalışmanın ana materyalini oluşturmaktadır. Türün yaprağı ve çiçekleri Şekil 1'de sunulmuştur.
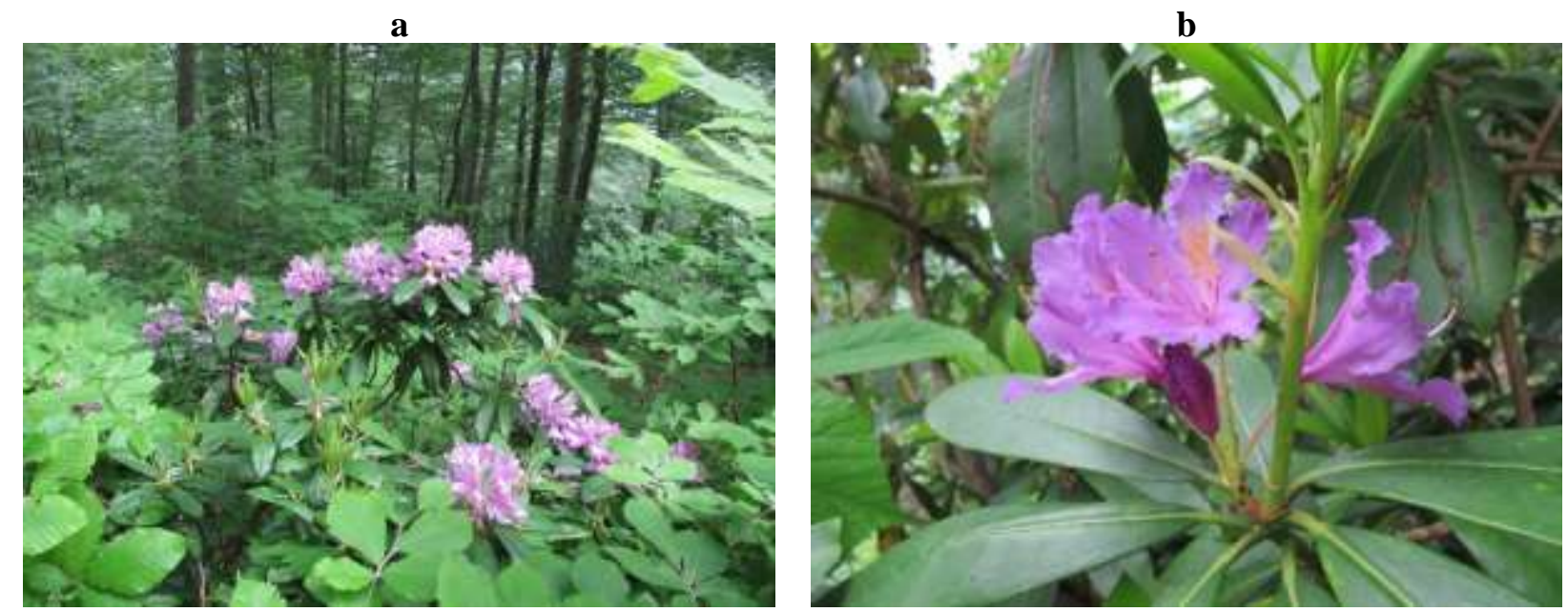

Şekil 1 R. ponticum L.yaprakları (a) (iNaturalist 2020a) ve çiçekleri (b) (iNaturalist 2020b)

\section{Yöntem}

\section{Çevresel Değişkenler ve Tür Verileri}

Çalışmanın ilk aşamasında mor çiçekli orman gülünün coğrafi yayılışını temsil eden noktaların koordinatları harita üzerinde işaretlenmiştir. Rhododendron ponticum L. 'nin coğrafi yayııısıını temsil eden 66 noktanın koordinatları literatür bilgilerinden, çevrimiçi veri tabanları (GBIF 2020) ile Flora of Turkey (Davis 1965) ve Orman Bakanlığı'nın Biyod verileri (BIYOD 2020) kullanılarak belirlenmiş ve QGIS 3.16.0 programında QMS eklentisi ile sağlanan Google Satellite Hybrid yüksek konumsal çözünürlüklü $(5 \mathrm{~m})$ harita üzerinde işaretlenmiştir (Şekil 2).
Ülkemizde Kuzey Anadolu sıradağlarının kuzeye dönük yamaçları ve Trakya-Istranca Dağları'ndaki nemli alanlarda yayılış gösteren mor çiçekli ormangülünün genel yayılışı Bulgaristan, Kafkaslar ve Lübnan'ı da kapsamaktadır (Akkemik 2014). $R$. ponticum L. herdemyeşil ve 10 metreye kadar uzayabilen bir tür olarak mor çiçekleri ile dikkat çekicidir (Özbucak ve ark. 2009, Akkemik 2014). 


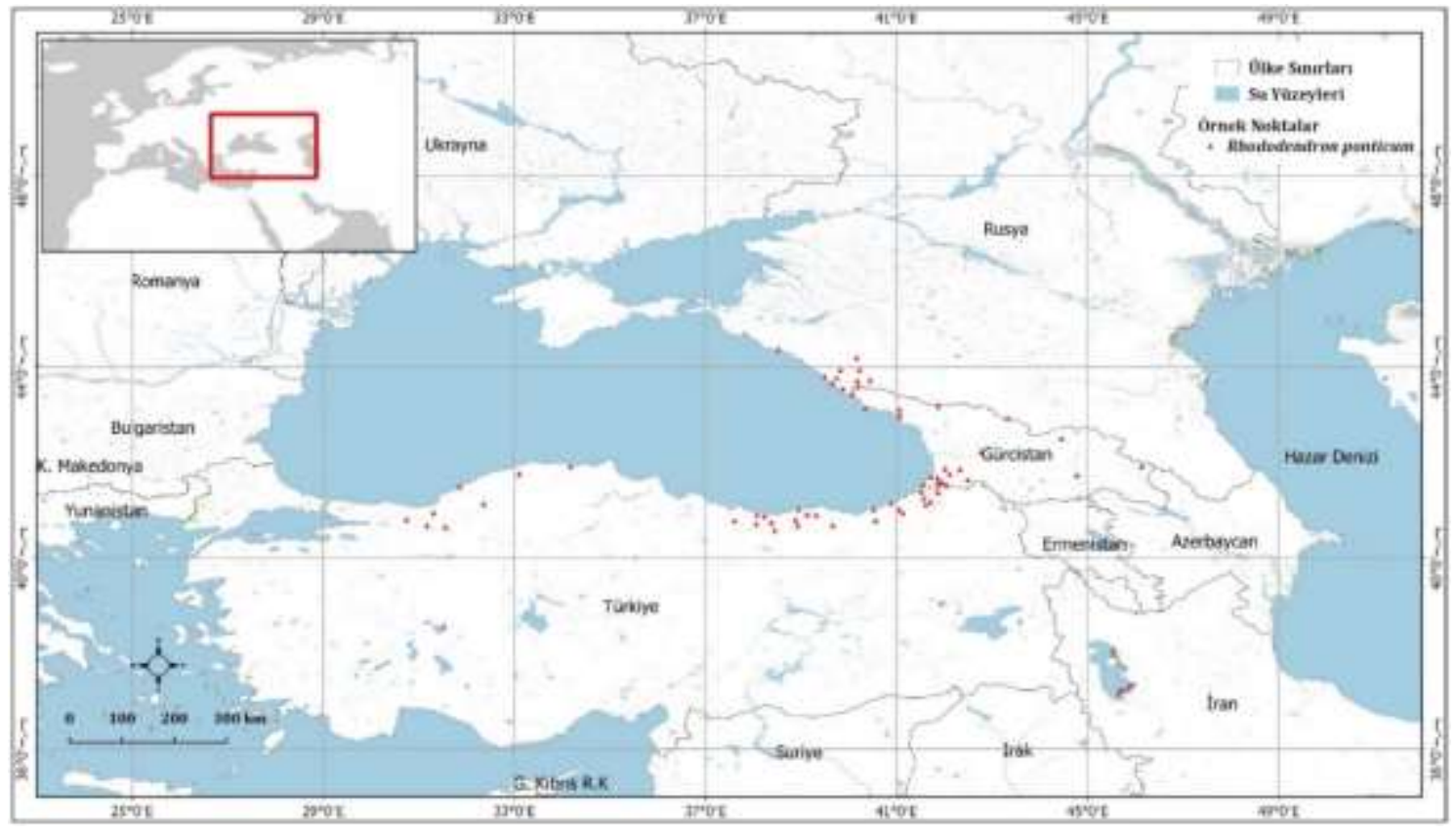

Şekil 2. Çalışma alanında R. ponticum L.'ye ait örnek noktalar

Çizelge 1. Biyoklimatik değişkenler (WorldClim 2020)

\begin{tabular}{ll} 
Kodlar & Tanımlar \\
\hline Bio 1 & Yılık ortalama sıcaklık \\
Bio 2 & Günlük ortalama değişim aralığı (ortalama aylık sıcaklık) \\
Bio 3 & İzotermallik \\
Bio 4 & Mevsimsel sıcaklık (standart sapmax100) \\
Bio 5 & En sıcak ayın en yüksek sıcaklığı \\
Bio 6 & En soğuk ayın en az sıcaklığı \\
Bio 7 & Yıllık sıcaklık değişim aralığı (Bio 5 - Bio 6) \\
Bio 8 & En nemli çeyreğin ortalama sıcaklığı \\
Bio 9 & En kurak çeyreğin ortalama sıcaklığı \\
Bio 10 & En sıcak çeyreğin ortalama sıcaklığı \\
Bio 11 & En soğuk çeyreğin ortalama sıcaklığı \\
Bio 12 & Yıllık yağış miktarı \\
Bio 13 & En nemli ayın yağış miktarı \\
Bio 14 & En kurak ayın yağış miktarı \\
Bio 15 & Mevsimsel yağış miktarı \\
Bio 16 & En nemli çeyreğin yağış miktarı \\
Bio 17 & En kurak çeyreğin yağış miktarı \\
Bio 18 & En sıcak çeyreğin yağış miktarı \\
Bio 19 & En soğuk çeyreğin yağış miktarı \\
\hline
\end{tabular}

Çalışmada türlerin gelecekteki yayılış alanını tahmin etmek amacıyla iklim modeli olarak CNRM/CERFACS modelleme grubu tarafından geliştirilen CNRM-CM6-1 iklim modeli kullanılmıştır. Çalışmada senaryo olarak Hükümetler Arası iklim Değişikliği Paneli'nin VI Değerlendirme Raporunda'ki (IPCC6) daha geniş bir gelecek tahmini sağlamak amacıyla CMIP6 için bir dizi yeni senaryo oluşturulmuştur. Bu senaryolar Shared Socioeconomic Pathways olarak (SSPS) SSP1-2.6, SSP2-4.5, SSP4-6.0 ve SSP5-8.5 şeklinde ifade edilmektedir. Çalışmada SSP2 4.5 ile SSP5 8.5 senaryolarına ait 20412060 ile 2081-2100 periyotları kullanılmıştır.

\section{İstatistiksel Analiz ve Modelleme Yöntemi}

Modelin tahmin gücünü azaltan çoklu doğrusal bağlantı (multicollienarity) sorununu (Zhang ve Liu 2017) çözmek amacıyla modelde kullanılan var verilerine ait 19 bioklimatik değişkene SPSS 25.0 paket istatistik programında Pearson korelasyon testi uygulanmıştır (Sillero 2011). Bu test sonucunda aralarında Pearson korelasyon katsayısı $(r)$ değeri \pm 0.8 ve üstü olan değişkenlerden biri modelden çıkarılarak (Yang ve ark. 2013, Cao ve ark. 2016) çoklu doğrusal bağlantı problemi çözülmüştür.

Çalışmada küçük örneklem büyüklükleri ile daha yüksek performans göstermesi nedeniyle korelatif makine öğrenmesi modellerinden biri olan ve maximum entropi algoritmasını temel alan MaxEnt 3.41 yazılımı kullanılmıştır. MaxEnt algoritması, mevcut bilgi durumunu en iyi temsil eden olasılık dağılımının, kesin olarak belirtilen önceki veriler bağlamında en büyük entropiye sahip olduğunu belirten maksimum entropi ilkesine dayanmaktadır. 
MaxEnt 3.4.1. programında modelleme prosedürü olarak, türe ait var verilerinden ( 66 nokta) $\% 25$ 'i test verisi olarak ayrılmış, arka plan nokta sayısı 30000, yineleme sayısı 10 (Replicates=10) ve yineleme çalıştırma tipi olarak alt örnek seçilmiştir (Replicated run type=Subsample). Çıktı formatı logistic (output format=logistic) olarak belirtilmiş ve nokta sayısı 30-80 arasında olduğu için Linear, Quadratic ve Hinge özellikleri işaretlenerek program çalıştırıımıştır. Modelin performansını belirlemek için Receiver Operating Characteristic (ROC) analizinden elde edilen Area Under the ROC Curve (AUC) değerinden faydalanılmıştır. Elde edilen AUC değeri, doğru ayarlanmış bir modelde rastgele seçilen grid hücresinin varlığının tahmini olasılığı olarak yorumlanabilir. AUC tüm olası eşiklerle modelin başarııını tanımlamaktadır. Eğer bu değer AUC> 0.5 ise modelin rastgele bir tahminden daha iyi performans gösterdiğini ifade etmektedir (Phillips ve Elith 2010). AUC test değeri 1'e ne kadar yakınsa ayrım o kadar iyi, model hassas ve tanımlayıcıdır (Phillips vd., 2006). AUC değerini yorumlamak için $A U C \geq 0.9=$ çok iyi, $0.9>A U C \geq 0.8$ = iyi ve $A U C<0.8=$ zayıf şeklinde eşik değerleri tanımlanmıştır (Gassó ve ark. 2012, Hosmer Jr ve ark. 2013). Son olarak çevresel değişkenlerin katkı derecesini belirlemek amacıyla, MaxEnt modelleme programında Jackknife testi seçeneği kullanılmıştır (Pearson ve ark. 2007, Shcheglovitova ve Anderson 2013). $\mathrm{Bu}$ seçenek her bir bağımsız değişkenin modelin oluşturulmasındaki önem derecelerini belirlemeye olanak tanımaktadır.

Model sonuçları QGIS 3.10.4 programı ile raster/vektör dönüşümü fonksiyonu kullanılarak dağılım haritalarına dönüştürülmüştür. MaxEnt modelinde bir türün alanda bulunma durumu 0-1 arasında bir değer ile belirlenmektedir. Değerler 1'e yaklaştıkça türün potansiyel olarak o alanda bulunma durumu artmaktadır. Güncel ve gelecek için oluşturulan potansiyel dağılım haritalarında yayılış alanı için uygunluk düzeyi "0" uygun değil, "0-0.25" çok az uygun, "0.25-0.50" az uygun, "0.500.75 " uygun ve "0.75-1" çok uygun alanlar olacak şekilde sınıflandırılmış ve bu sınıflandırmaya göre günümüz ve gelecek senaryolarına göre tahmini yayılış alanları km² olarak hesaplanmıştır (Çoban ve ark. 2020).

En son aşamada ise güncel potansiyel yayılış alanı ile SSP2 4.5 ve SSP5 8.5 senaryolarında $2041-2060$ ve 2081-2100 periyotları için tahmini yayılış alanları arasında karşılaştırma yapmak amacıyla değişim analizi yapılmıştır. Değişimlerin belirlenmesi için uygunluk değerleri $0=0$, 0 $0.25=1,0.25-0.50=2 \quad 0.50-0.75=3$ ve $0.75-1=4$ şeklinde kodlanarak sınıflandırılmış ve bu verilere kesişim (intersection) fonksiyonu uygulanmıştır. Uygunluk değerlerine göre 0-0 olan alanlar uygun değil, aynı sınıfta olan alanlar değişim yok, bir üst sınıfa geçen alanlar kazanç, bir alt sınıfa geçen alanlar kayıp olarak adlandırımış ve kapladıkları alanlar $\mathrm{km}^{2}$ olarak hesaplanarak değişim haritaları oluşturulmuş ve böylece değişimin yönü ve büyüklüğü ortaya konulmuştur.

\section{BULGULAR}

Çoklu doğrusal bağlantı sorununu çözmek için yöntemde belirtildiği şekilde yapılan Pearson korelasyon testi sonuçlarına göre modelin tahmin gücünü zayıflatan değişkenler çıkarılmış ve Bio1, Bio2, Bio3 Bio4, Bio8, Bio9, Bio14 ve Bio15 değişkenleri modelde kullanılmıştır. Tekrarlı çalışmalar için ortalama AUC 0.981 ve standart sapma ise 0.005 olarak bulunmuştur (Şekil 3). Bu sonuç modelin rastgele tahminden çok daha yüksek bir tahmin gücü olduğunu göstermektedir. 


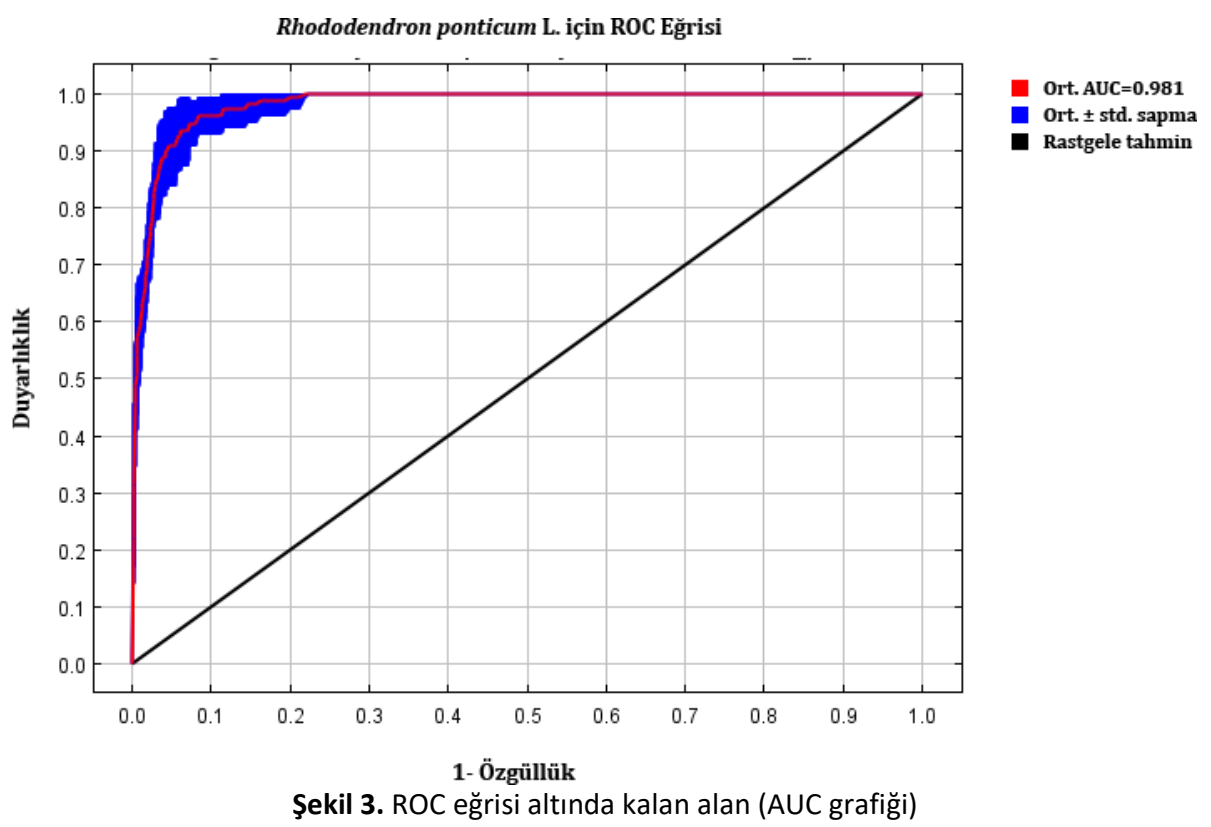

10 yinelemeli yapılan çalışmanın Jackknife testi ortalama sonuçlarına göre tek başına kullanıldığında en yüksek kazancı sağlayan biyoklimatik değişken en kurak ayın yağış miktarıdır (Bio14). Bu nedenle kendi başına en yararlı bilgiye sahip olduğu kabul edilmektedir. Göz ardı edildiğinde kazancı en çok azaltan çevresel değişken ise en nemli çeyreğin ortalama sıcaklığıdır (Bio8), bu nedenle Bio8 değişkeni diğer değişkenlerde bulunmayan en fazla bilgiye sahip olduğu düşünülmektedir (Şekil 4).

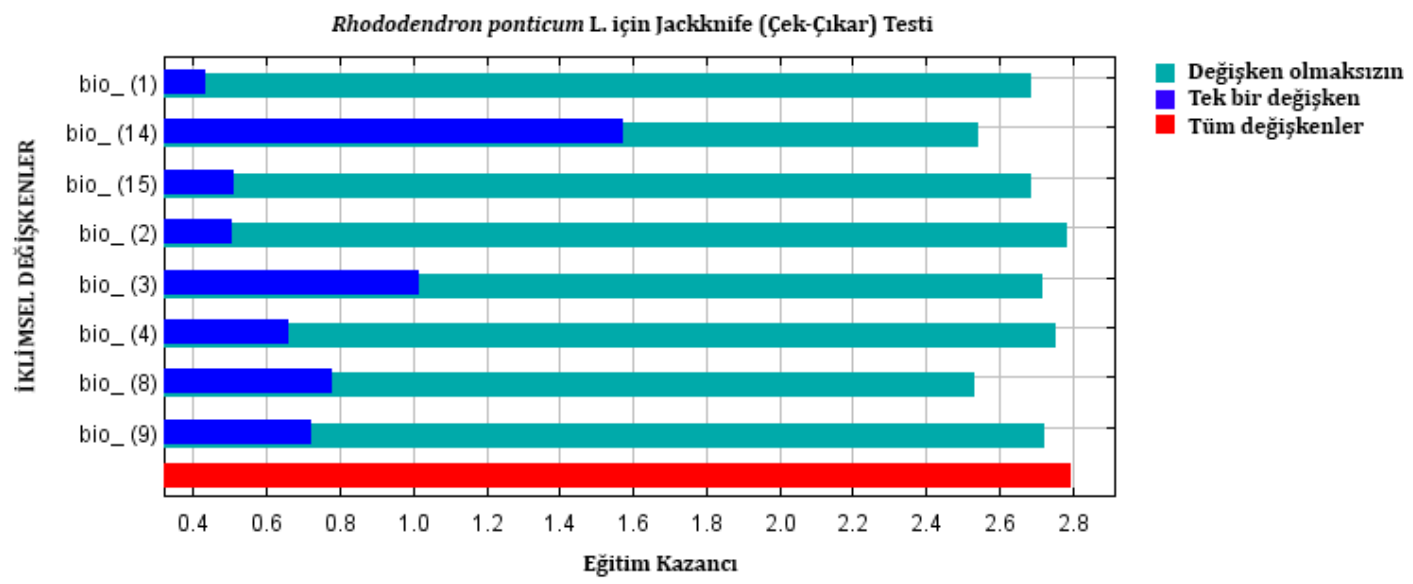

Şekil 4. Jackknife grafiği

R. ponticum L.'nin günümüz ve gelecek potansiyel coğrafi dağılımlarına ait tahmin modelleri Şekil 5, 6 ve 7'de verilmiştir. Üretilen model uygunluk düzeylerine göre Uygun değil (0) Çok az uygun (0-0.25) Az uygun (0.25$0.50)$, uygun (0.50-0.75) ve çok uygun (0.75-1.0) olmak üzere beş farklı seviyede sınıflandırılmış ve QGIS 3.16.1 programı kullanılarak haritalandırılmıştır. Elde edilen haritalarda $R$. ponticum L.'nin günümüz ve gelecekteki konumsal dağılımı izlenebilmektedir.
Model çıktıları sonucunda elde edilen güncel dağılım haritası incelendiğinde $R$. ponticum L.'nin doğal yayılış alanları ile yüksek oranda benzerlik gösterdiği görülmektedir. Şekil 5 incelendiğinde Bulgaristan'ın Karadeniz kıyıları ile Türkiye'de Karadeniz kıyıları boyunca, Gürcistan'ın Batı kısımları ile Rusya Federasyonu'nun Güney Karadeniz kıyılarına paralel olarak uzanan bölgede ile Kırım'da yayılış gösterdiği görülmektedir. 


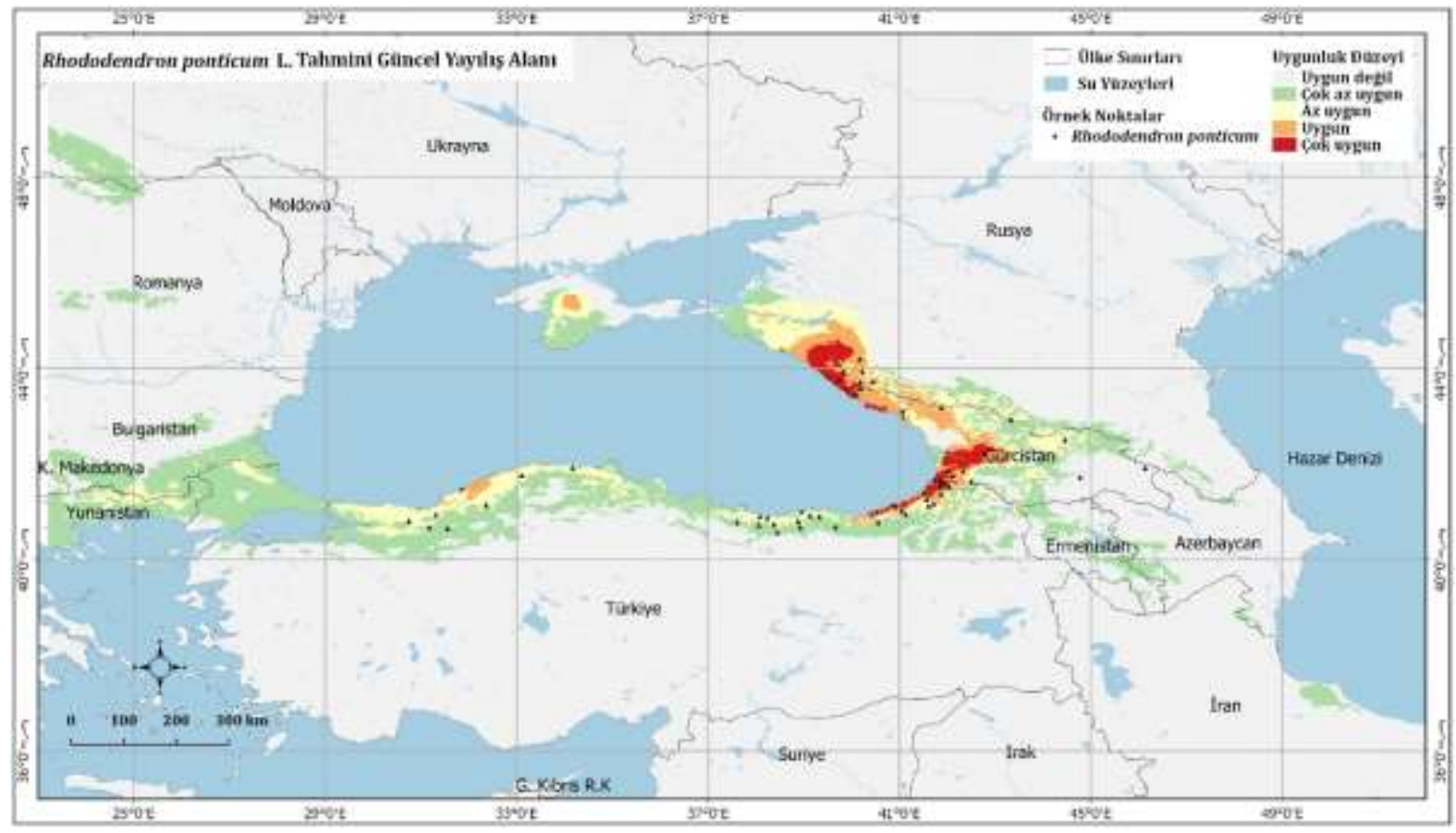

Şekil 5. R. ponticum L.'nin potansiyel güncel yayılış alanı

iklim değişikliği senaryolarına göre 2041-2060 (Şekil 6) ve 2081-2100 (Şekil 7) periyotları için üretilen model haritalarında tahmin edilen gelecek coğrafi dağıımın konumsal yapısı incelendiğinde, türün yayılış gösterebileceği alanlarda 2041-2060 periyotlarında artış 2081-2100 periyotlarında ise azalan bir eğilim gösterdiği izlenmektedir (Çizelge 2). Günümüz için çok uygun ve uygun olarak sınıflandırılan alanlar $33848 \mathrm{~km}^{2}$ alan kaplarken SSP2 4.5 senaryosuna göre 2041-2060 periyotunda bu alanların toplamı $38055 \mathrm{~km}^{2 \prime}$ ye çıkacağı, 2081-2100 periyotunda ise $32421 \mathrm{~km}^{21}$ ye düşeceği tahmin edilmektedir. SSP2 4.5 senaryosuna göre daha kötümser bir senaryo olan SSP5 8.5 senaryosuna göre ise uygun ve çok uygun olarak sınıflandırılan alanlar 20412060 periyotunda $35999 \mathrm{~km}^{2}$ iken 2081-2100 periyotunun $28745 \mathrm{~km}^{2}$ olarak tahmin edilmektedir. Türün özellikle Türkiye'deki yayılış alanı, nispeten orta ve yüksek sıcaklık artışlarının neden olacağı iklimsel değişimden olumsuz yönde etkileneceği Gürcistan ve Rusya'da ise yayılış alanındaki daralmayla birlikte tür daha kuzeye doğru yayııış göstereceği söylenebilir.

Çizelge 2. Rhododendron ponticum L.'nin Günümüz ve CNRM-CM6-1 iklim modeline göre SSP2 4.5 ve SSP5 8.5 senaryoları 2041-2060 ve 2081-2100 periyotlarına göre alansal yayılışı $\left(\mathrm{km}^{2}\right)$

\begin{tabular}{|c|c|c|c|c|c|}
\hline Uygunluk Düzeyi & Güncel & $\begin{array}{l}\text { SSP2 } 4.5 \\
2041-2060\end{array}$ & $\begin{array}{l}\text { SSP2 } 4.5 \\
2081-2100\end{array}$ & $\begin{array}{l}\text { SSP5 } 8.5 \\
2041-2060\end{array}$ & $\begin{array}{l}\text { SSP5 } 8.5 \\
2081-2100\end{array}$ \\
\hline Uygun Değil & 3499189 & 3511732 & 3424421 & 3533185 & 3187148 \\
\hline Çok Az Uygun & 216507 & 203648 & 303008 & 200455 & 547852 \\
\hline Az Uygun & 68505 & 64615 & 58200 & 48411 & 54305 \\
\hline Uygun & 20582 & 29138 & 26443 & 25667 & 26312 \\
\hline Çok Uygun & 13266 & 8917 & 5978 & 10332 & 2433 \\
\hline Toplam & 3818049 & 3818049 & 3818049 & 3818049 & 3818049 \\
\hline
\end{tabular}




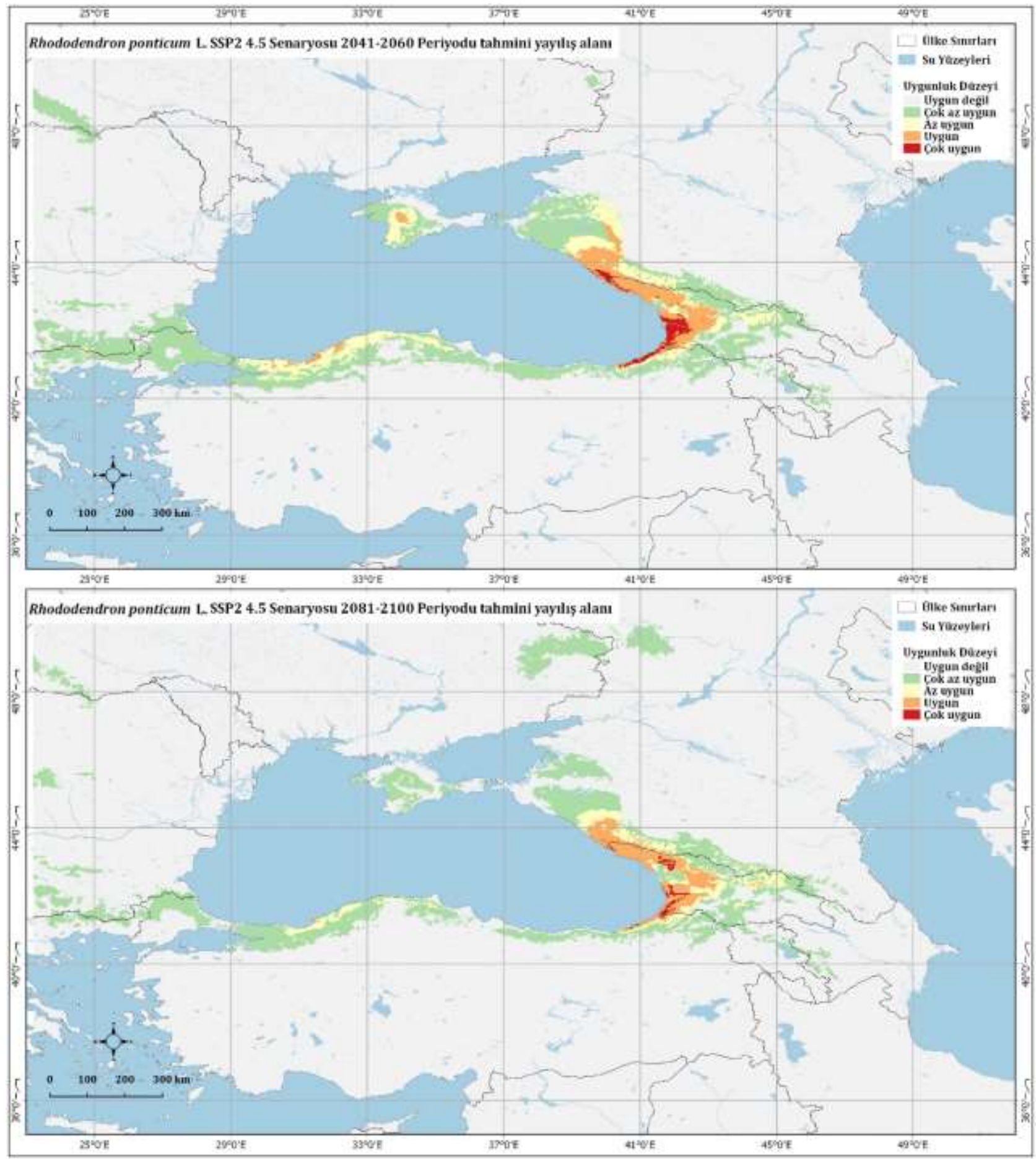

Şekil 6. $R$. ponticum L.'nin CNRM-CM6-1 iklim modeline göre SSP2 4.5 senaryosu 2041-2060 ve 2081-2100 periyotları için tahmini yayılış alanları 


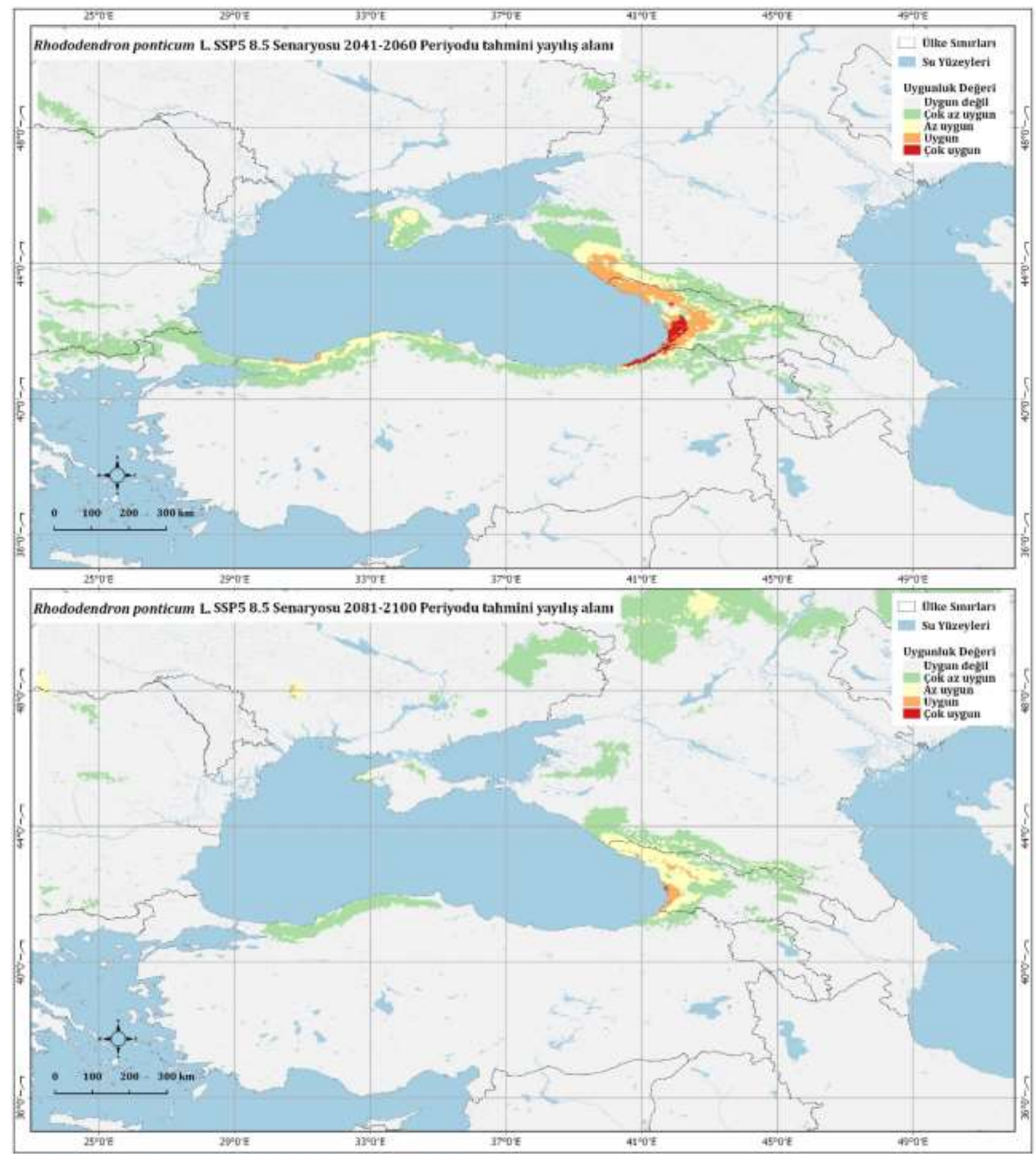

Şekil 7. R. ponticum L.'nin CNRM-CM6-1 iklim modeline göre SSP5 8.5 senaryosu 2041-2060 ve 2081-2100 periyotları için tahmini yayılış alanları

\section{Değişim Analizi}

Çalışmada hedef türün yöntemde belirtildiği şekliyle yapılan günümüz ve gelecek iklim senaryolarına ait periyotlarla yapılan değişim analizi çıktıları Şekil 8 ve Şekil 9 da verilmiştir. R. ponticum L.'nin SSP2 4.5 ve SSP5 8.5 iklim değişikliği senaryolarına göre 2041-2060 ve 20812100 periyotları için tahmin edilen potansiyel coğrafi yayılışında değişimin yönü ve büyüklüğü görülebilmektedir. Çizelge 3'e göre SSP2 4.5 senaryosu 2041-2060 periyotunda $62689 \mathrm{~km}^{2}$ lik bir alan bir üst sınıfa geçerek kazanç olarak hesaplanırken $139617 \mathrm{~km}^{2}$ kayıp olarak hesaplanmıştır. SSP2 4.5 senaryosu 20812100 periyotunda ise kazanç olarak değerlendirilen alanlar $66985 \mathrm{~km}^{2}$, kayıp olarak değerlendirilen alanlar $210457 \mathrm{~km}^{2}$ olarak hesaplanmıştır. SSP5 8.5 senaryosu 
2041-2060 periyotunda $42852 \mathrm{~km}^{2}$ lik bir alan bir üst sınıfa geçerek kazanç olarak hesaplanırken $189803 \mathrm{~km}^{2}$ lik bir alan bir alt uygunluk sınıfına geçerek kayıp olarak hesaplanmıştır. SSP5 8.5 senaryosu 2081-2100 periyotunda ise kazanç olarak değerlendirilen alanlar 188027 km², kayıp olarak değerlendirilen alanlar 286485 $\mathrm{km}^{2}$ olarak hesaplanmıştır.

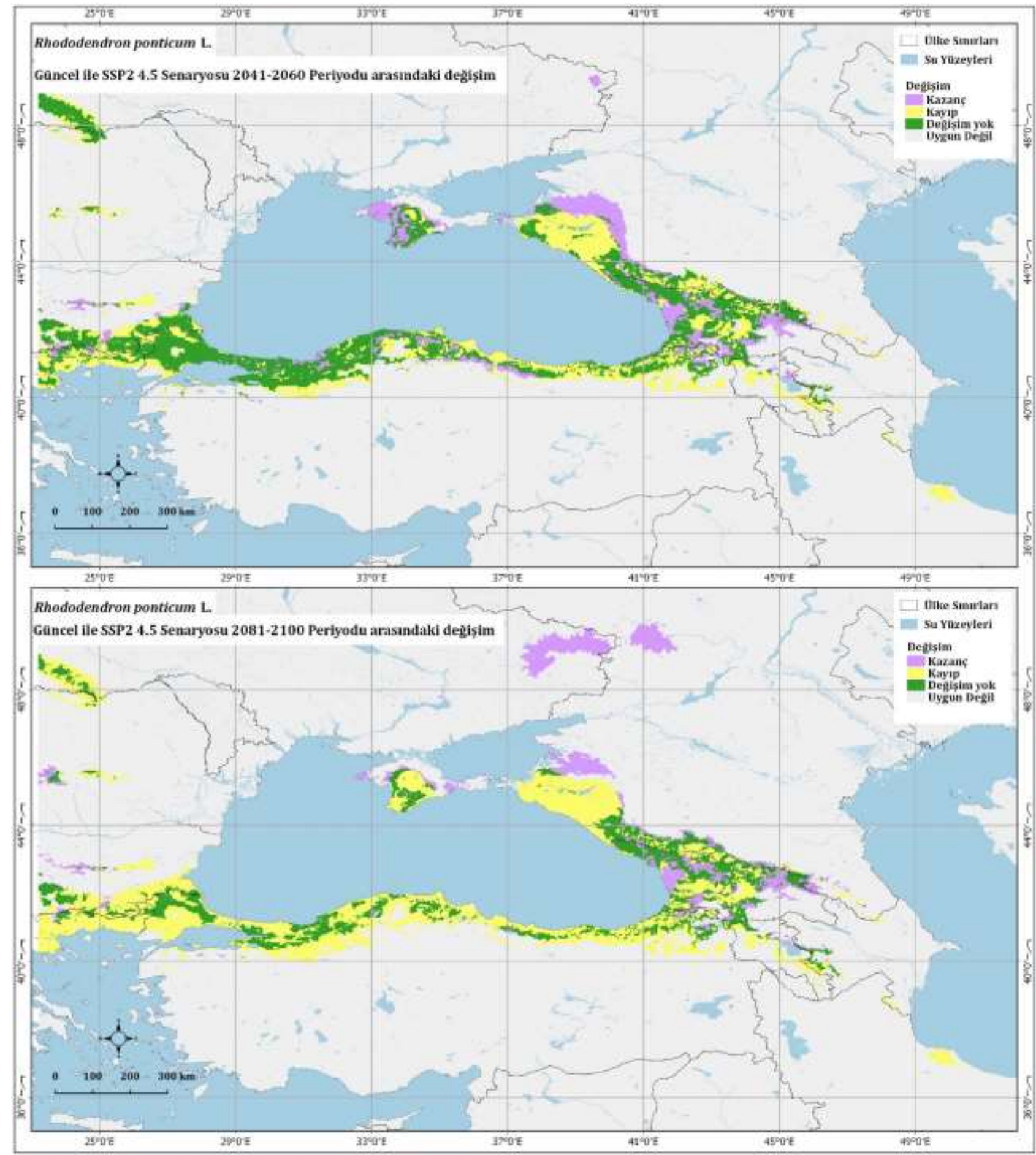

Şekil 8. $R$. ponticum L.'nin günümüz ile CNRM-CM6-1 iklim modeline göre SSP2 4.5 senaryosu 2041-2060 ve 2081-2100 periyotları için tahmini yayılış alanları arasındaki değişimler 


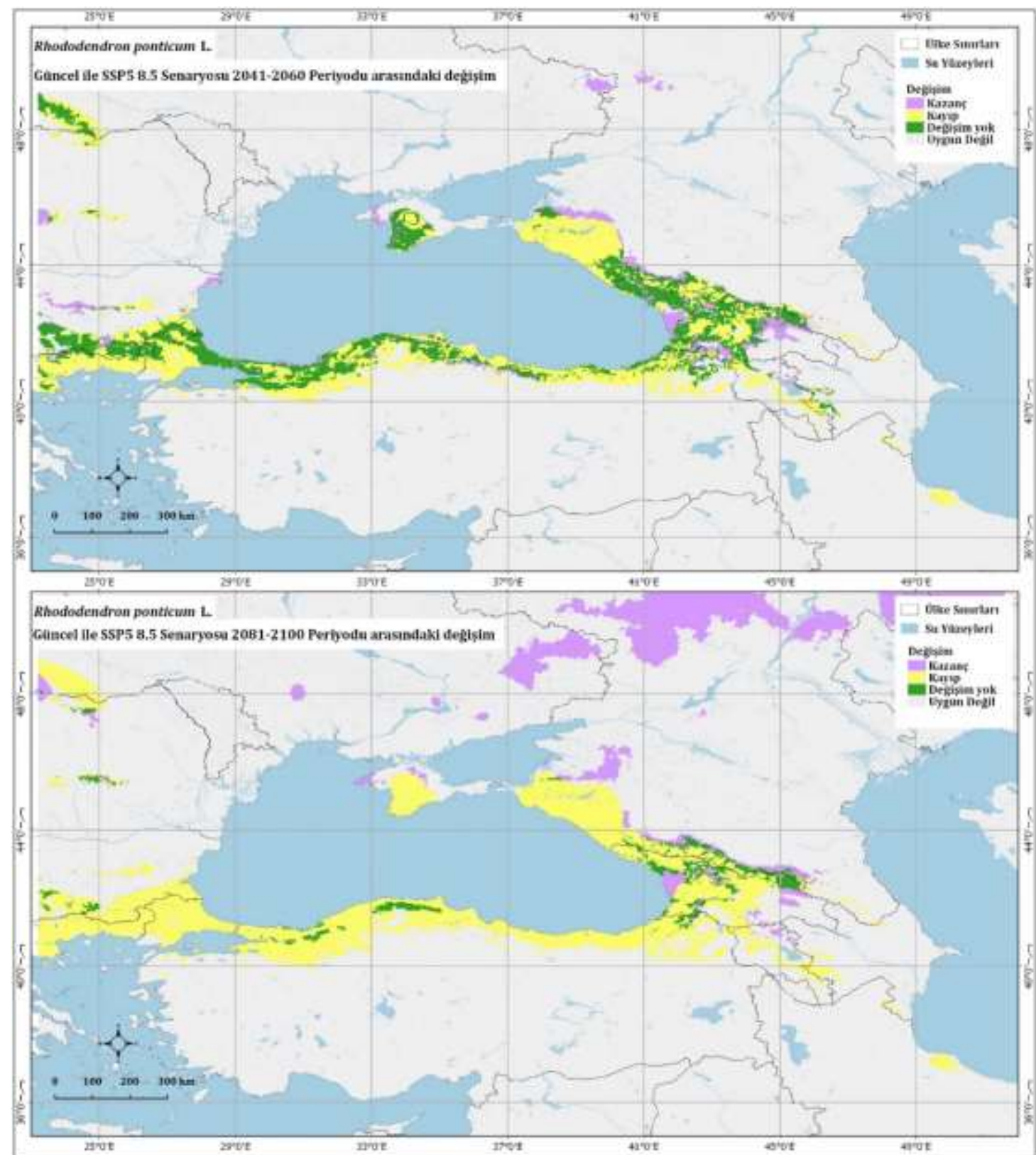

Şekil 9. R. ponticum L.'nin günümüz ile CNRM-CM6-1 iklim modeline göre SSP5 8.5 senaryosu 2041-2060 ve 2081-2100 periyotları için tahmini yayılış alanları arasındaki değişimler

Çizelge 3 R. ponticum L.'nin günümüz ile CNRM-CM6-1 iklim modeline göre SSP2 4.5 ve SSP5 8.5 senaryoları 2041-2060 ve 2081-2100 periyotları arasındaki değişimlerin alansal büyüklükleri $\left(\mathrm{km}^{2}\right)$

\begin{tabular}{lllll}
\hline & SSP2 4.5 & SSP2 4.5 & SSP5 8.5 & SSP5 8.5 \\
Değişim tipi & $\mathbf{2 0 4 1 - 2 0 6 0}$ & $\mathbf{2 0 8 1 - 2 1 0 0}$ & $\mathbf{2 0 4 1 - 2 0 6 0}$ & $\mathbf{2 0 8 1 - 2 1 0 0}$ \\
\hline Kazanç & 62689 & 66985 & 42852 & 188027 \\
Kayı̀ & 139617 & 210457 & 189803 & 286485 \\
Değişim yok & 162107 & 99228 & 123290 & 31351 \\
Uygun Değil & 3453637 & 3441379 & 3462104 & 3312186 \\
Toplam & 3818049 & 3818049 & 3818049 & 3818049 \\
\hline
\end{tabular}

\section{TARTIŞMA}

Gelecekteki iklim koşulları altında tür temelli doğa koruma yönetimi için geliştirilen mevcut önerilerin çoğu, tamamen tür dağılım modellerinden (TDM) türetilen senaryolara ve tahminlere dayanmaktadır. TDM'ler regresyon veya veri madenciliğine dayanan tekniklerdir ve bitki fizyolojisine bilgiler bulundurmamalarına rağmen türlerin dağılım özelliklerine ilişkin yararlı hipotezlerin üretilmesini sağlarlar (Walentowski ve ark. 2017). 
Hipotezler, genel olarak türlerin coğrafi aralık değişimlerine, bu değişimlerin neden olduğu ekosistem içerisindeki tür etkileşimlerine, habitat parçalanmasına ya da bölgesel adaptasyonlara odaklanmıştır (Garzón ve ark. 2019, Nascimbene ve ark. 2020). Hipotezlerin ortaya attığı genel tartışma ise, iklim değişikliğine bağlı olarak tür içi etkileşimlerin azalmasına, tür yok oluşları nedeniyle habitat parçalanmasının artmasına ve türlerin adaptasyon yeteneklerinin azalmasına yöneliktir (Rogers ve ark. 2017). Ancak bu tartışmaların çürütüldüğü çalışmalar da bulunmaktadır. Nadir de olsa, bazı durumlarda türlerin iklimsel koşullara zamanla direnci artabilir ve yaşanan direnç artışı, hedef türün diğer türlerle olan etkileşiminde pozitif yönde değişiklikler gösterebilir (Yang ve ark. 2015, Peterson ve ark. 2019). Bu nedenle, iklim tahmin modellemesinde gerçekçi sonuçlar gösterecek güçlü algoritmaların kullanılmasında fayda vardır. Bu çalışmada, maksimum entropi algoritması yardımıyla R. ponticum L.'nin potansiyel yayılış alanlarının modellenmesinde CMIP6 projesine ait CNRM-ESM-1 iklim değişim modeli kullanılmıştır. Türün SSP2 4.5 ve SSP5 8.5'e senaryolarına göre $2041-2060$ ve $2081-2100$ periyotlarına ait potansiyel yayılış alanının modellenmesinde biyoikimsel değişkenler kullanılmıştır. $\mathrm{Bu}$ modellerin tahmin gücü ve gerçeklik oranı RCP modellerine kıyasla daha yüksek olduğu için çalışmada elde edilen sonuçların, doğruluğu yüksek bilgi sağladığı öngörülmektedir (Eyring ve ark. 2016, Hausfather 2019). Bu çalışmada kullanılan senaryoların tümüne göre model sonuçları (SSP2 4.5 2041-2060, SSP2 4.5 2081-2100, SSP5 8.5 2041-2060, SSP5 8.5 2081-2100) incelendiğinde, tür kaybının kazançtan daha fazla olduğu dikkat çekmiştir. Dolayısıyla, bu durum gelecekte $R$. ponticum L. habitatlarının tehdit/tehlike altında olabileceğini göstermektedir.

Modelleme aşamasına dâhil edilecek değişken sayısına dikkat edilmesi önerilmektedir. Çünkü belirli değişkenlerin modellemeye dâhil edilmesi veya modellemenin dışında tutulması, zayıf model performansına ve yanlış tahminlere neden olabilir. Bu nedenle, çevresel değişkenlerin belirlenmesi ve seçilmesi sırasında, türün ekolojik nişine ilişkin uzman görüşü ve bilgisi mümkün olduğunca dikkate alınmalıdır. Ayrıca, gelecekteki çalışmalarda, türlerin edafik gereksinimleri hakkında bilgi sahibi olunması önerilmiştir (Garcia ve ark 2013).

$\mathrm{Bu}$ makalede sunulan kapsama paralel olarak, $R$. ponticum L. türlerine odaklanan benzer çalışmalar bulunmaktadır. Örneğin; İngiltere'nin batısındaki Galler'de istilacı özelliği ile tanınan bu türün 2050 yılına kadar habitat uygunluğunun azalacağı yönünde bir tahmin yapılmıştır. Maksimum entropi algoritmasından yararlanılan bu çalışmada, $R$. ponticum L. dağııımın belirleyen en önemli değişkenlerin arazi örtüsü ve topografik değişkenler olduğunu belirtilmiştir. Bu çalışmanın, gelecekteki tür dağılış eğilimlerini gösteren haritalarla birlikte, $R$. ponticum L. dağılımını kontrol etmek ve istilacılığını önlemeye yönelik uygulamaların geliştirilmesine yardımcı olacağı vurgulanmıştır (Manzoor ve ark. 2018). Çin'de yürütülen ve maksimum entropi algoritmasına dayanan bir başka çalışmada, $R$. ponticum L.'nin Çin'in kuzeybatısına doğru kayacağı sonucuna ulaşılmıştır. Ayrıca türün, 2070 yılında beklenen iklim ve arazi kullanım değişikliğinden genel olarak olumsuz etkileneceği öngörülmüştür (Yu ve ark. 2019). Buna ek olarak, $R$. ponticum L. türünün genel olarak daralış gösteren dağılımının, Himalayalar'daki biyolojik çeşitlilik ve ekosistem işleyişi için potansiyel olarak negatif sonuçlara yol açacağı belirtilmiştir (Kumar 2012). Sonuç olarak, düşük rakımlarda ve bozulmuş habitatlarda yetişen türlere in-situ ve ex-situ koruma için öncelik verilmesi gerektiğine dikkat çekilmiştir. Kumar (2012), $R$. ponticum L. türünün coğrafi yayılışının modellenmesi için biyoiklimsel değişken seçimi konusunda, uygun değişkenlerin kullanılmasının önemine atıf yaparak benzer konuda daha fazla araştırmaya ihtiyaç olduğunu vurgulamıştır. Bu makalede sunulan yöntemde değişken indirgenmesinde gösterilen nedenlerin, bu ihtiyacın giderilmesine net bir katkı sağladığı düşünülmektedir.

Gelecekteki iklim koşullarına bağlı habitat değişiklikleri, tehdit altındaki türlerin bulunma potansiyeli olan alanları korumak için uygun adaptasyon stratejileri gerektirir. İklim değişikliğinin olası olumlu ve olumsuz etkileri dikkatle ele alınmalı ve uygun adaptasyon stratejilerinin uygulanması için bir fırsat olarak görülmelidir. Örneğin, bazı türlerin uygun yaşam alanlarındaki potansiyel artış, iklim değişikliğinden kaynaklanan çeşitli baskılara 
dayanmalarına yardımcı olacaktır (Moukrim ve ark. 2019). Ya da bu durumun aksine, adaptasyon direnci düşük olan türler yok olma tehlikesi ile karşı karşıya kalacaktır.

Bu çalışmanın hedefleri arasında, gelecekteki potansiyel arazi kullanımı değişikliğine göre tür dağılımının modellenmesi yer almamaktadır. Ancak, iklim değişiminin yanı sıra değişen arazi örtüsü de türün yayılışı konusunda etkili olabilir. Dolayısıyla, farklı gelecek tahmin modelleri (Markov zinciri, Business-as-usual modeli vb.) ile arazi örtüsündeki olası değişiklikleri yansıtan modellemeler de iklim temelli tür yayııış çalışmalarına entegre edilebilir.

İklim değişikliğinin, doğal ekosistemler, ilişkili yaban hayatı ve insanlar üzerindeki etkileri ile uyum önlemlerinin yerel koşullara en iyi şekilde nasıl uyarlanabileceği konusunda hala büyük bilgi boşlukları vardır (Reside ve ark. 2019). Gelecekteki iklim koşulları karşısında tür dağııımı modellerinin geliştirilmesi ve mekânsal veri tabanlarının iyileştirilmesi, hem türlere hem de ekosistemlerine fayda sağlayacak bilim temelli koruma stratejilerinin üretilmesini destekleyebilir. Böylece peyzajda farklı ekosistemler arasındaki bağlantı korunabilir (Timpane-Padgham ve ark. 2017). Habitat yamaları arasındaki bağlantıların restorasyonu ve sürdürülmesi yoluyla daha küçük peyzaj yamaları arasında işlevsel bağlantı sağlanabilir. İlim senaryolarının tür dağılımına odaklandığı çalışmalara, habitatların çevresel çeşitlilik, bağlanabilirlik ve izolasyon açısından göreceli önemi de dahil edilebilir. Bu bağlamda, ekosistemler arasındaki tampon bölgelerde biyolojik koridorların ve ekolojik bağlantılılı̆ın değişen iklim koşullarına göre güçlendirilmesi gerekebilir. Koridorlarda bariyerlerin (yollar, yerleşim alanları, tarım alanları vb.) oluşturulması genetik alışverişin önüne geçebilir. Bu nedenle hem bariyerler hem de türlerin iklim değişikliği sonucu değişen coğrafi aralıklarının doğa koruma kapsamında ele alınması önerilmiştir. Bunun en etken yolu, iklim değişikliğine uyum çerçevesindeki koruma hedeflerinin çevre düzeni planına aktarılabilmesidir. Doğa koruma, yalnızca sınırları çeşitli ölçütlere göre belirlenmiş "korunan alan" statüsü olan alanları kapsamamalı, aynı zamanda iklim değişikliğine uyum sağlamada potansiyel tür dağılımlarını da dikkate almalıdır. Bu bakış açısı, peyzaj yönetiminde benimsendiği sürece, önemli habitatların korunması sağlanabilir. Peyzaj yönetiminin doğrudan iklim değişikliği azaltım ve etkilerine uyuma odaklanması, bu ve buna benzer araştırma makalelerinden elde edilen bulguları tamamen dikkate alarak ulusal ve yerel iklim değişikliği uyum ve azaltım strateji ve eylem planlarına dâhil edilmesi gerekmektedir. Teori bilgilerin pratiğe aktarılmasında, türlerin yayılış potansiyellerine göre yayılıs alanlarının koruma değerleri belirlenerek peyzaj yönetim faaliyetlerinin arttırılması önerilmiştir. Örneğin; türlerin iklim değişikliğine adaptasyonu konusunda bilgi havuzları oluşturulabilir. Nesli tehdit altında olan türlerin yayılış gösterdiği alanlarda türün devamlılı̆ını sağlamak amacıyla ağaçlandırma çalışmaları yapılabilir. Ağaçlandırma çalışmalarında türün asosiasyon oluşturabileceği ve sosyobilitesi yüksek doğal türler de seçilebilir. Ayrıca, koruma temelli yaklaşımlar çerçevesinde insanların ihtiyaç duyduğu ekosistem hizmetlerinin sürdürülebilir olması sağlanabilir (von Holle ve ark. 2020). Böylece, teoriye yönelik çıktılar pratiğe aktarılarak peyzaj planlamanın hedefleri gerçekleştirilebilir.

\section{SONUÇ}

Ekolojik niş modellemesi, küresel iklim değişikliği çerçevesinde doğa korumaya yönelik yönergeleri oluşturmak için verimli ve yaygın olarak kullanılabilecek bir yaklaşım olarak kabul edilmiştir. Ayrıca, iklim değişikliği senaryoları için girdi oluşturan yüksek kaliteli coğrafi yayılış verileri, habitat uygunluklarının belirlenmesinde ve etkili koruma eylemlerinin uygulanmasında önemli bir rol oynamaktadır. Bu çalışma, $R$. ponticum L.'nin günümüz ve gelecekteki iklim koşullarına göre coğrafi dağııımını başarılı bir şekilde modellemiş, bu kapsamda makine öğrenmesi tekniği olan maksimum entropi algoritmasını kullanmıştır. Mekânsal çözünürlük, modelin uygun habitatları doğru bir şekilde tahmin etmesini kolaylaştırmıştır. Bu araştırmanın bulguları, iklim değişikliği karşısında ormangüllerini korumak için benimsenmesi gereken stratejileri yönlendirebilecek peyzaj yönetimi için önemli bilgiler sağlamaktadır. Sonuç olarak, iki iklim senaryosuna (SSP2 4.5 ve SSP5 8.5) dayalı tahminler, iklim değişikliği nedeniyle mevcut $R$. ponticum L.'nin habitat uygunluğunun 2041-2060 ve 2081-2100 zaman 
aralıklarında önemli ölçüde azalacağını göstermiştir. Bu nedenle, türün sürdürülebilirliğine yönelik planlama kararları alınmalıdır.

\section{KAYNAKLAR}

Abdelaal M, Fois M, Fenu G, Bacchetta G (2019) Using MaxEnt modeling to predict the potential distribution of the endemic plant Rosa arabica Crép. in Egypt. Ecological Informatics 50:6875. https://doi.org/10.1016/j.ecoinf.2019.01.003

Akkemik Ü (2014) Türkiye'nin doğal-egzotik ağaç ve çalıları I. Orman Genel Müdürlüğü Yayınları, Ankara

Akyol A, Orucu OK, Arslan ES (2020) Habitat suitability mapping of stone pine (Pinus pineaL.) under the effects of climate change. Biologia

Arslan ES, Akyol A, Örücü ÖK, Sarıkaya AG (2020) Distribution of rose hip (Rosa canina L.) under current and future climate conditions. Reg Environ Change 20:107. https://doi.org/10.1007/s10113020-01695-6

Austin M (2007) Species distribution models and ecological theory: A critical assessment and some possible new approaches. Ecological Modelling 200:1-19. https://doi.org/10.1016/j.ecolmodel.2006.07.005

BIYOD (2020) BIYOD - Biyolojik Çeşitlilik ve Odun DIşı Orman Ürünleri Veri Tabanı. Tarım ve Orman Bakanlığı Orman Genel Müdürlüğü, Ankara

Bouchard M, Aquilué N, Périé C, Lambert M-C (2019) Tree species persistence under warming conditions: $A$ key driver of forest response to climate change. Forest Ecology and Management 442:96-104. https://doi.org/10.1016/j.foreco.2019.03.040

Cao B, Bai CK, Zhang LL, et al (2016) Modeling habitat distribution of Cornus officinalis with Maxent modeling and fuzzy logics in China. J Plant Ecol 9:742-751. https://doi.org/10.1093/jpe/rtw009

Chen I-C, Hill JK, Ohlemüller R, et al (2011) Rapid Range Shifts of Species Associated with High Levels of Climate Warming. Science 333:1024-1026. https://doi.org/10.1126/science.1206432

Çoban HO, Örücü ÖK, Arslan ES (2020) MaxEnt Modeling for Predicting the Current and Future Potential Geographical Distribution of Quercus libani Olivier. Sustainability 12:2671. https://doi.org/10.3390/su12072671

Dagnino D, Guerrina M, Minuto L, et al (2020) Climate change and the future of endemic flora in the South Western Alps: relationships between niche properties and extinction risk. Reg Environ Change 20:121. https://doi.org/10.1007/s10113-020-01708-4

Dai J, Roberts DA, Stow DA, et al (2020) Mapping understory invasive plant species with field and remotely sensed data in Chitwan, Nepal. Remote Sensing of Environment 250:112037. https://doi.org/10.1016/j.rse.2020.112037

Davis PH (1965) Flora of Turkey and The East Aegean Islands - I. Edinburgh University Press, Edinburgh

Dawson TP, Jackson ST, House Jl, et al (2011) Beyond Predictions: Biodiversity Conservation in a Changing Climate. Science 332:5358. https://doi.org/10.1126/science.1200303

Dimobe K, Ouédraogo A, Ouédraogo K, et al (2020) Climate change reduces the distribution area of the shea tree (Vitellaria paradoxa CF Gaertn.) in Burkina Faso. Journal of Arid Environments 181:104237

Djalante R (2019) Key assessments from the IPCC special report on global warming of $1.5^{\circ} \mathrm{C}$ and the implications for the Sendai framework for disaster risk reduction. Progress in Disaster Science 1:100001. https://doi.org/10.1016/j.pdisas.2019.100001
Dyderski MK, Paź S, Frelich LE, Jagodziński AM (2018) How much does climate change threaten European forest tree species distributions? Global Change Biology 24:1150-1163. https://doi.org/10.1111/gcb.13925

Ehrlén J, Morris WF (2015) Predicting changes in the distribution and abundance of species under environmental change. Ecology Letters 18:303-314. https://doi.org/10.1111/ele.12410

Elith J, Leathwick JR (2009) Species distribution models: ecological explanation and prediction across space and time. Annual review of ecology, evolution, systematics 40:677-697

Eyring V, Bony S, Meehl GA, et al (2016) Overview of the Coupled Model Intercomparison Project Phase 6 (CMIP6) experimental design and organization. Geoscientific Model Development 9:1937-1958. https://doi.org/10.5194/gmd-9-1937-2016

Fei S, Desprez JM, Potter KM, et al (2017) Divergence of species responses to climate change. Science Advances 3:e1603055. https://doi.org/10.1126/sciadv.1603055

Ferrarini A, Alsafran MHSA, Dai J, Alatalo JM (2019) Improving niche projections of plant species under climate change: Silene acaulis on the British Isles as a case study. Clim Dyn 52:1413-1423. https://doi.org/10.1007/s00382-018-4200-9

Fortunel C, Paine CET, Fine PVA, et al (2014) Environmental factors predict community functional composition in Amazonian forests. Journal of Ecology 102:145-155. https://doi.org/10.1111/13652745.12160

Garcia K, Lasco R, Ines A, et al (2013) Predicting geographic distribution and habitat suitability due to climate change of selected threatened forest tree species in the Philippines. Applied Geography 44:12-22. https://doi.org/10.1016/j.apgeog.2013.07.005

Garzón MB, Robson TM, Hampe A (2019) $\Delta$ TraitSDMs: species distribution models that account for local adaptation and phenotypic plasticity. New Phytologist 222:1757-1765. https://doi.org/10.1111/nph.15716

Gassó N, Thuiller W, Pino J, Vilà M (2012) Potential Distribution Range of Invasive Plant Species in Spain. NeoBiota 12:25

GBIF (2020) Rhododendron ponticum L. in GBIF Secretariat (2019). GBIF Backbone Taxonomy. Checklist dataset https://doi.org/10.15468/39omei accessed via GBIF.org on 2020$12-01$

Hausfather Z (2019) CMIP6: the next generation of climate models explained. In: Carbon Brief. https://www.carbonbrief.org/cmip6the-next-generation-of-climate-models-explained. Accessed 8 Oct 2020

Hernandez PA, Graham CH, Master LL, Albert DL (2006) The effect of sample size and species characteristics on performance of different species distribution modeling methods. Ecography 29:773-785. https://doi.org/10.1111/j.0906-7590.2006.04700.x

Hosmer Jr DW, Lemeshow S, Sturdivant RX (2013) Applied logistic regression. John Wiley \& Sons

iNaturalist (2020a) Gözlemci Grzegorz Grzejszczak Tarih: Mayıs 31, 2016 12:11 PM HST Yer: Adżaria, Gruzja (Google, OSM). In: iNaturalist. https://www.inaturalist.org/photos/15547467. Accessed 30 Nov 2020

iNaturalist (2020b) Gözlemci Grzegorz Grzejszczak Tarih: Mayıs 31, 2016 12:11 PM HST Yer: Adżaria, Gruzja (Google, OSM). In: iNaturalist. https://www.inaturalist.org/photos/15546233. Accessed 30 Nov 2020

IPCC (2014) Climate Change 2014: Synthesis Report. Contribution of Working Groups I, II and III to the Fifth Assessment Report of the Intergovernmental Panel on Climate Change. Geneva, Switzerland

Kaky E, Nolan V, Alatawi A, Gilbert F (2020) A comparison between Ensemble and MaxEnt species distribution modelling approaches 
for conservation: A case study with Egyptian medicinal plants. Ecological Informatics 60:101150. https://doi.org/10.1016/j.ecoinf.2020.101150

Kim J, Lee DK, Kim HG (2020) Suitable trees for urban landscapes in the Republic of Korea under climate change. Landscape and Urban Planning 204:103937. https://doi.org/10.1016/j.landurbplan.2020.103937

Kramer-Schadt S, Niedballa J, Pilgrim JD, et al (2013) The importance of correcting for sampling bias in MaxEnt species distribution models. Divers Distrib 19:1366-1379. https://doi.org/10.1111/ddi.12096

Kumar P (2012) Assessment of impact of climate change on Rhododendrons in Sikkim Himalayas using Maxent modelling: limitations and challenges. Biodivers Conserv 21:1251-1266. https://doi.org/10.1007/s10531-012-0279-1

Li G, Huang J, Guo H, Du S (2020) Projecting species loss and turnover under climate change for 111 Chinese tree species. Forest Ecology and Management 477:118488. https://doi.org/10.1016/j.foreco.2020.118488

Manzoor SA, Griffiths G, lizuka K, Lukac M (2018) Land Cover and Climate Change May Limit Invasiveness of Rhododendron ponticum in Wales. Front Plant Sci 9:. https://doi.org/10.3389/fpls.2018.00664

Merow C, Smith MJ, Silander JA (2013) A practical guide to MaxEnt for modeling species' distributions: what it does, and why inputs and settings matter. Ecography 36:1058-1069. https://doi.org/10.1111/j.1600-0587.2013.07872.x

Moukrim S, Lahssini S, Rhazi M, et al (2019) Climate change impacts on potential distribution of multipurpose agro-forestry species: Argania spinosa (L.) Skeels as case study. Agroforest Syst 93:12091219. https://doi.org/10.1007/s10457-018-0232-8

Nascimbene J, Benesperi R, Casazza G, et al (2020) Range shifts of native and invasive trees exacerbate the impact of climate change on epiphyte distribution: The case of lung lichen and black locust in Italy. Science of the Total Environment 735:139537

Norberg A, Abrego N, Blanchet FG, et al (2019) A comprehensive evaluation of predictive performance of 33 species distribution models at species and community levels. Ecological Monographs 89:e01370. https://doi.org/10.1002/ecm.1370

Oliver TH, Smithers RJ, Beale CM, Watts K (2016) Are existing biodiversity conservation strategies appropriate in a changing climate? Biological Conservation 193:17-26. https://doi.org/10.1016/j.biocon.2015.10.024

Örücü ÖK (2019) Phoenix theophrasti Gr.'nin iklim değişimine bağlı günümüz ve gelecekteki yayılış alanlarının MaxEnt Modeli ile tahmini ve bitkisel tasarımda kullanımı. Türkiye Ormancılık Dergisi 20:274-283. https://doi.org/10.18182/tjf.613205

Özbucak TB, Türkiş S, Çakmak A (2009) Ordu çevresinde yayılış gösteren bazı Rhododendron türleri üzerine ekolojik bir çalışma. Research Journal of Biology Sciences 2:71-77

Pearson RG, Raxworthy CJ, Nakamura M, Townsend Peterson A \% J of biogeography (2007) Predicting species distributions from small numbers of occurrence records: a test case using cryptic geckos in Madagascar. 34:102-117

Peterson ML, Doak DF, Morris WF (2019) Incorporating local adaptation into forecasts of species' distribution and abundance under climate change. Global Change Biology 25:775-793. https://doi.org/10.1111/gcb.14562

Phillips SJ, Anderson RP, Schapire RE \%J E modelling (2006) Maximum entropy modeling of species geographic distributions. 190:231259

Phillips SJ, Elith J (2010) POC plots: calibrating species distribution models with presence-only data. Ecology 91:2476-2484
Qin AL, Liu B, Guo QS, et al (2017) Maxent modeling for predicting impacts of climate change on the potential distribution of Thuja sutchuenensis Franch., an extremely endangered conifer from southwestern China. Glob Ecol Conserv 10:139-146. https://doi.org/10.1016/j.gecco.2017.02.004

Reside AE, Critchell K, Crayn DM, et al (2019) Beyond the model: expert knowledge improves predictions of species' fates under climate change. Ecological Applications 29:e01824. https://doi.org/10.1002/eap.1824

Rogers BM, Jantz P, Goetz SJ (2017) Vulnerability of eastern US tree species to climate change. Global Change Biology 23:3302-3320. https://doi.org/10.1111/gcb.13585

Rojas Briceño NB, Cotrina Sánchez DA, Barboza Castillo E, et al (2020) Current and Future Distribution of Five Timber Forest Species in Amazonas, Northeast Peru: Contributions towards a Restoration Strategy. Diversity 12:305. https://doi.org/10.3390/d12080305

Romero GQ, Gonçalves-Souza T, Kratina P, et al (2018) Global predation pressure redistribution under future climate change. Nature Climate Change 8:1087-1091. https://doi.org/10.1038/s41558-018-0347-y

Sarıkaya A, Örücü ÖK (2019) Prediction Of Potential And Future Distribution Areas Of Anatolian Chesnut (Castanea Sativa Mill.) By Usıng Maximum Entropy (Maxent) Modeling Depending On Climate Change In Turkey. International Journal of Ecosystems and Ecology Science (IJEES) 9:699-708

Scheffers BR, Meester LD, Bridge TCL, et al (2016) The broad footprint of climate change from genes to biomes to people. Science 354:. https://doi.org/10.1126/science.aaf7671

Scheper J, Holzschuh A, Kuussaari M, et al (2013) Environmental factors driving the effectiveness of European agri-environmental measures in mitigating pollinator loss - a meta-analysis. Ecology Letters 16:912-920. https://doi.org/10.1111/ele.12128

Shcheglovitova M, Anderson RP (2013) Estimating optimal complexity for ecological niche models: A jackknife approach for species with small sample sizes. Ecological Modelling 269:9-17. https://doi.org/10.1016/j.ecolmodel.2013.08.011

Sillero N (2011) What does ecological modelling model? A proposed classification of ecological niche models based on their underlying methods. Ecological Modelling 222:1343-1346

Simi E, Moreno PI, Villa-Martínez R, et al (2017) Climate change and resilience of deciduous Nothofagus forests in central-east Chilean Patagonia over the last 3200 years. Journal of Quaternary Science 32:845-856. https://doi.org/10.1002/jqs.2948

Thapa A, Wu RD, Hu YB, et al (2018) Predicting the potential distribution of the endangered red panda across its entire range using MaxEnt modeling. Ecol Evol 8:10542-10554. https://doi.org/10.1002/ece3.4526

Timpane-Padgham BL, Beechie T, Klinger T (2017) A systematic review of ecological attributes that confer resilience to climate change in environmental restoration. PLOS ONE 12:e0173812. https://doi.org/10.1371/journal.pone.0173812

von Holle B, Yelenik S, Gornish ES (2020) Restoration at the landscape scale as a means of mitigation and adaptation to climate change. Curr Landscape Ecol Rep 5:85-97. https://doi.org/10.1007/s40823-020-00056-7

Walentowski H, Falk W, Mette T, et al (2017) Assessing future suitability of tree species under climate change by multiple methods: a case study in southern Germany. Annals of Forest Research 60:101-126-126. https://doi.org/10.15287/afr.2016.789

Williams JW, Jackson ST (2007) Novel climates, no-analog communities, and ecological surprises. Frontiers in Ecology and the Environment 5:475-482. https://doi.org/10.1890/070037 
WorldClim (2020) Global climate and weather data - WorldClim. https://worldclim.org/data/index.html. Accessed 1 Dec 2020

Yang J, Pedlar JH, McKenney DW, Weersink AJ (2015) The development of universal response functions to facilitate climate smart regeneration of black spruce and white pine in Ontario, Canada. https://doi.org/10.1016/j.foreco.2014.12.001

Yang XQ, Kushwaha SPS, Saran S, et al (2013) Maxent modeling for predicting the potential distribution of medicinal plant, Justicia adhatoda L. in Lesser Himalayan foothills. Ecol Eng 51:83-87. https://doi.org/10.1016/j.ecoleng.2012.12.004
Yu F, Wang T, Groen TA, et al (2019) Climate and land use changes will degrade the distribution of Rhododendrons in China. Science of The Total Environment 659:515-528. https://doi.org/10.1016/j.scitotenv.2018.12.223

Zhang T, Liu G (2017) Study of methods to improve the temporal transfer ability of niche model. Journal of China Agricultural University 22:98-105

Zhao H, Zhang H, Xu C (2020) Study on Taiwania cryptomerioides under climate change: MaxEnt modeling for predicting the potential geographical distribution. Global Ecology and Conservation 24:e01313. https://doi.org/10.1016/j.gecco.2020.e0131 